\title{
САТЕЛЛИТНЫЕ СЧЕТА КАК ИНСТРУМЕНТ МАКРОЭКОНОМИЧЕСКОГО УПРАВЛЕНИЯ РАЗВИТИЕМ ТУРИЗМА
}

\author{
(C) 2021 Радван Юунан \\ аспирант Высшей инженерно-экономической школы \\ Санкт-Петербургский политехнический университет Петра Великого, Россия, Санкт-Петербург \\ E-mail: younan-r@hotmail.com
}

(C) 2021 Гузикова Людмила Александровна

доктор экономических наук, профессор Высшей инженерно-экономической школы

Санкт-Петербургский политехнический университет Петра Великого, Россия, Санкт-Петербург

guzikova@mail.ru

Роль туризма в экономиках развивающихся стран в последние десятилетия быстро росла, однако вопросы ее количественной оценки остаются открытыми. В статье рассматриваются вспомогательные (сателлитные) счета туризма как инструмент макроэкономической оцени и управления развитием туризма. Описаны преимущества, которые могут получить страны-дестинации от разработки и внедрения таких счетов и условия, которые при этом должны быть выполнены.

Ключевые слова: туризм, макроэкономическое управление, управление туризмом, вспомогательные (сателлитные) счета туризма, региональные вспомогательные счета туризма, развивающиеся страны

Значимость туризма как направления экономической деятельности все больше возрастает в связи с ростом его доли в ВВП многих стран и влиянием, которое он оказывает на развитие инфраструктуры и многих секторов экономической деятельности, в первую очередь, транспорта, строительства и связи, сельского хозяйства [1]. Кроме того, туризм является источником валютных доходов и возможностей трудоустройства. Основой макроэкономического управления развитием туризма является оценка его экономического вклада в показатели страны-дестинации.

Однако оценка вклада туризма в макроэкономические показатели страны как отправная точка для выработки управленческих воздействий осложняется информационными пробелами, к числу которых авторы [2] относят:

- недостаточное знание ключевых факторов, влияющих на конкурентоспособность дестинации;

- недостаточное знание об экономическом вкладе туризма в экономику страны;

- отсутствие адекватных моделей для оценки экономических последствий различных вариантов политики, влияющих на индустрию туризма.

Заполнению указанных пробелов должна способствовать целостная, точная, достоверная, актуальная, доступная, интерпретируемая,

обеспечивающая пространственно-временную сопоставимость результатов процессов и явлений система сбора и обработки статистической информации о туристской отрасли. Александрова А.Ю. пишет.: «Туристским администрациям статистика необходима для определения исходного состояния туристского рынка, выработки государственной политики в сфере туризма, разработки концепций, стратегий и программ развития туризма и мер по их реализации, мониторинга и оценки эффективности управленческой деятельности в сфере туризма. Бизнесу также необходим емкий информационный ресурс для выбора целевых сегментов туристского рынка, формирования новых туристских продуктов, корректировки маркетинговой стратегии, принятия оперативных инвестиционных и иных управленческих решений» [3]. Для потенциальных инвесторов статистическая информация является базой оценки инвестиционной привлекательности и эффективности вложения средств в отдельные объекты, территории и туристскую отрасль в целом [3].

Цель настоящего исследования состоит в выявлении перспектив и направлений использования вспомогательных (сателлитных) счетов туризма (tourism satellite accounts, TSA) в развивающихся странах, в которых они до настоящего времени не используются. 
С начала 21 века основным инструментом макроэкономической оценки туризма являются вспомогательные (сателлитные) счета туризма (tourism satellite accounts, TSA) [4]. Вследствие ограничений существующих систем учета все большее число стран разрабатывают и внедряют TSA в соответствии с методологической базой (TSA-RMF) [5], разработанной и утвержденной Статистической комиссией Организации Объединенных Наций. Цель настоящего исследования состоит в выявлении перспектив и направлений использования TSA в развивающихся странах, в которых они до настоящего времени не используются.

В соответствии с [5] деятельность в сфере туризма отражается на отдельном счете, то есть на счете, который является вспомогательным элементом основных национальных счетов. TSA предназначены для сопоставления спроса и предложения в сфере туризма и позволяют исследовать взаимосвязь между туризмом и другими видами экономической деятельности в рамках национальных счетов, экстрагируя связанную с туризмом экономическую деятельность, которая включается в национальные счета, но не определяется как туризм [6]. Отражая разные аспекты спроса на товары и услуги, которые в экономике могут быть связаны с туризмом, TSA дают возможность установить оперативную связь с предложением таких товаров и услуг в рамках экономики [7].

TSA представляют собой набор сводных таблиц, содержащих соответствующие данные:

- расходы на въездной, внутренний и выездной туризм;

- расходы на внутренний туризм;

- производственные счета отраслей туризма;

- валовая добавленная стоимость (ВДС) и валовой внутренний продукт (ВВП), относящиеся к туризму;

- занятость;

- инвестиции;

- государственное потребление;

- немонетарные показатели.

TSA позволяют проследить денежные потоки в туристской отрасли от потребителя до производящей единицы или поставщика. При этом они выделяют и идентифицируют туристские подотрасли или группы поставщиков, которые производят или импортируют товары и услуги, приобретаемые посетителями [8].

Отсутствие информации об экономическом значении туризма и влиянии его расширения на экономику традиционно мешало выработке политики в отношении туризма в развивающихся странах, где национальные статистические данные часто имеют ограниченный объем и сомнительную точность. Но даже если в национальную статистику будут внесены улучшения, в системе национальных счетов невозможно идентифицировать туризм как единую отрасль и определить его ценность для экономики, поскольку туристская деятельность «скрыта» в других видах деятельности (размещение, транспорт, телекоммуникации и т.д.). Таким образом, оценки экономического вклада туризма, основанные только на системах национальных счетов и выделяющие только сектора, прямо связанные с туризмом, скорее всего, будут значительно занижать общие расходы туристов и, следовательно, экономическое значение туризма в целом.

Однако, поскольку TSA представляет описание значимости прямого туристического спроса в экономике в конкретный период времени, они не обеспечивают полной оценки воздействия на экономику изменений в расходах на туризм. TSA не принимает во внимание, например, возможные факторные ограничения, которые могут создавать препятствия для роста туризма в ответ на увеличение туристического спроса, или влияние, которое изменение цен и заработной платы может иметь на другие (не туристические) отрасли [6]. В [9] поясняется, что при измерении вклада индустрии туризма в ВBП на основе TSA результаты должны корректироваться с учетом косвенных эффектов и промежуточного потребления.

В [10] указывается, что исследователи и политики не всегда понимают, что невозможно оценить более широкие экономические последствия изменения туристического спроса, используя средние значения TSA. Изменения происходят на пределе и включают межотраслевые и другие эффекты в масштабах всей экономики, поэтому изменение в экономике в целом почти всегда будет меньше, чем изменение ВВП и занятости в сфере туризма [10].

Внедрение TSA в систему национальных счетов может принести существенную пользу развивающимся странам, включая арабские государства, которые, как большинство развивающихся стран, нуждаются в подробной статистике, отражающей реалии туризма, и в повышении компетентности статистиков в этом 
секторе, Как указывается в [11], многие арабские государства имеют различные, разрозненные и нечеткие статистические данные, которые не дают четкого представления о ситуации в сфере туризма. Более того, имеются противоречия в концепциях и определениях, используемых в арабских странах для управления сферой туризма [11].

Можно указать преимущества внедрения TSA в развивающихся странах, стремящихся к управляемому развитию туризма как значимой отрасли национального хозяйства:

1. TSA формируют макроэкономические агрегаты, характеризующие размер и экономический вклад туризма, - валовую добавленную стоимость туризма и валовой внутренний продукт туризма, аналогичные соответствующим агрегатам для экономики в целом и для других видов экономической деятельности и согласующиеся с ними. Выделение туризма в рамках национальной системы учета позволяет включить его в макроэкономический анализ как самостоятельную сферу деятельности.

2. TSA измеряют взаимосвязь туризма с другими отраслями. Выявляя источники валовой добавленной стоимости, создаваемой в экономике для удовлетворения спроса туристов и путешественников, TSA позволяют изучать взаимосвязь между туризмом и другими отраслями и выявлять, какие отрасли экономики и в какой степени зависят от туризма.

3. TSA поддерживают межотраслевые сравнения. Поскольку TSA выводятся из общей структуры системы национальных счетов, они позволяют сравнивать туризм с другими отраслями экономики, используя согласованные и признанные на международном уровне принципы учета. TSA позволяют сравнивать туристскую индустрию с другими отраслями с точки зрения размера, экономических показателей, занятости и вклада в национальную экономику. На основе TSA могут быть разработаны инструменты сравнительного анализа и показатели, позволяющие отдельным операторам сектора сравнивать свои показатели производительности, роста и доходов с отраслевыми нормами [12].

4. TSA поддерживают международные сравнения и позволяют получать оценки, сопоставимые с международно-признанными макроэкономическими агрегатами и наборами данных, TSA облегчают сравнение данных и показателей туристической индустрии разных стран.

5. TSA обеспечивают достоверность оце- нок вклада туризма в национальную экономику. В качестве статистического инструмента, совместимого с международными стандартами учета, TSA должны способствовать повышению доверия к туризму как к экономическому сектору. Они могут быть полезны средствам массовой информации, помогая повысить осведомленность о туризме и его вкладе в национальную экономику, а также всем заинтересованным лицам, способствуя лучшему пониманию экономического значения туризма и его влияния на все отрасли, связанные с производством товаров и услуг, востребованных туристами [12].

6. TSA являются инструментом улучшения стратегического управления и планирования в индустрии туризма. В статистике и национальных информационных системах туризм не получает должного отражения, что снижает возможности анализа туристической политики как в государственном, так и в частном сектоpax. TSA дают политикам и администраторам всех уровней представление о туризме и его вкладе в экономику и являются инструментом для разработки более эффективной политики в отношении туризма и отдельных его аспектов, в частности, занятости [13]. Помогая определить ценность туризма для экономики, TSA также могут помочь в разработке конкурентных стратегий в этом секторе.

Для туристических компаний наибольший интерес представляют показатели доходности, а оценки вклада туризма представляют наибольший интерес для менеджеров дестинации и более широкого сообщества [14].

Доходность как норма прибыли для рынка в целом или определенной рыночной ниши может быть рассчитана следующим образом:

Доходность рыночной ниши = Валовая операционная прибыль от продаж в рыночной нише / Потребление туризма в рыночной нише

TSA может использоваться для оценки вклада туризма в валовой внутренний продукт, валовую добавленную стоимость или занятость как на уровне отрасли, так и на уровне рыночной ниши. Можно определить показатель вклада на уровне отрасли или для рыночной ниши следующим образом:

Доходность рыночной ниши = Вклад в ВВП (ВДС, занятость) продаж в определенной нише рынка / Потребление туризма в рыночной нише 
Авторы [15] указывают на необходимость инвестиций в поддержку национальных TSA. При разработке TSA необходимо учитывать особенности национальных систем статистики и перспектив их унификации в условиях глобализации. Также целесообразно предусмотреть возможность применения подхода к субнациональным регионам, особенно для стран, в рамках которых имеются различающиеся по условиям развития туризма регионы. В [16] указывается, что несмотря на популярность TSA в качестве унифицированного метода измерения вклада туризма в национальную экономику, аккредитованного ООН и другими международными организациями, к субнациональным регионам TSA применяются редко. Распространение TSA на региональный уровень позволит оценить влияние туризма на отдельные регионы на основе высококаче- ственных и сопоставимых данных и, исходя их результатов оценки, формировать политику регионального развития на общегосударственном и региональном уровне с учетом экономического потенциала туризма $[17 ; 18]$.

По результатам проведенного анализа можно сделать следующие выводы,

1. Разработка и внедрение TSA в тех странах, где они до настоящего времени не используются, даст политикам и менеджерам туризма мощный инструмент макроэкономического управления и управления регионами.

2. Внедрение TSA потребует инвестиций, направленных на разработку проекта TSA с учетом структуры экономики страны и ее административно- территориального устройства и на проведение организационных изменений в системе национальной статистики.

\section{Библиографический список}

1. Shopova M. Tourism satellite accounts - an information basis for the analysis of tourism expenditure. // Економічний вісник Донбасу, 4(50), 2017, 18-23.

2. Dwyer L, Forsyth P., Dwyer W., 2015. Tourism and Economic Development: Three Tools of Analysis. DOI: 10.1080/02508281.2009.11081605

3. Александрова А.Ю.Формирование интегрированной системы статистики туризма в Российской Федерации //Вестник Московского университета. Серия 6: Экономика. 2017. № 1. С. 41-61.

4. Frechtling D.C., 2010. The Tourism Satellite Account. A Primer. Annals of Tourism Research, 37 (1), 136-153.

5. Tourism Satellite Account: Recommended Methodological Framework 2008. Luxembourg, Madrid, New York, Paris: Department of Economic and Social Affairs, United Nations, 2010.

6. Dwyer L., Forsyth P. and Spurr R., 2007. Contrasting the uses of TSAs and CGE models: measuring tourism yield and productivity. Tourism Economics. 13 (4), 537-551.

7. Лобан И. И., Шепелевич С. Н. Сателлитный счет по туризму: история развития и внедрение в Республике Беларусь // Вестник Белорусской государственной сельскохозяйственной академии. 2015. № 3. С. 32-38.

8. Фоменко Е.В., КошутинаА.А.Перспективы применения сателлитных счетов туризма // Естественногуманитарные исследования. 2014. № 3(5). С. 71-76.

9. Smeral E., 2006. Tourism Satellite Accounts: A Critical Assessment. Journal of Travel Research https://doi. org/10.1177/0047287506288887

10. Pratt S., 2013. Estimating Tourism Impacts using CGE Models: A Historical Review and Future Developments. DOI: 10.1142/9789814327084_0021

11. SESRIC, 2009. Report on the Workshop on Tourism Statistics Damascus. https://sesricdiag.blob.core.windows.net/ sesric-site-blob/imgs/news/image/Report_Tourism_Stat.pdf

12. Spurr, R., 2006. Tourism satellite accounts. In: L.Dwyer, \& P. Forsyth (Eds.), International handbook on the economics of tourism. Cheltenham, UK and Northampton, MA: Edward Elgar.

13. Jones, C., Munday A., Roberts A., 2003, Regional Tourism Satellite Accounts: A Useful Policy Tool?, Urban Studies, 40 (13), 2777-2794,

14. Salma, U., Heaney L., 2004. Proposed Methodology for Measuring Yield, Tourism Research Report, 6(1), 73-81,

15. Abrahão Rabahy, Décio Katsushighe Kadota, Glauber Eduardo de Oliveira Santos, Moisés Diniz Vassallo, Challenges to the Development of Tourism Satellite Accounts in Brazil Wilson https://www.iioa.org/conferences/17th/ papers/890206828_090609_165720_CHALLENGESTOTHEDEVELOPMENTOFTOURISMSATELLITEACCOUNTSINB RAZIL.PDF

16. Frenț, C., Frechtling, D.C., 2020, Regional tourism satellite accounts: towards international comparability, Tourism Review, Vol. ahead-of-print No. ahead-of-print. https://doi.org/10.1108/TR-07-2020-0315 
17. Brændvang A.K.,, Dybedal P., Johansen S., Sørensen K. Regional Satellite Accounts for Tourism Data, Concepts, Methods and Applications http://www-sre.wu.ac.at/ersa/ersaconfs/ersa01/papers/full/195.pdf

18. Jones C., Munday M., 2010. Tourism satellite accounts for regions? A review of development issues and an alternative. Economic Systems Research. Tourism Studies and Input-Output Analysis. 22 (4), 341-358. https://doi. org/10.1080/09535314.2010.526594 